\title{
Role of Different Concentrations of Morphine after Coronary Perfusion for Myocardial Protection
}

\author{
S Chen, J Xiong, Y Zhan, W Liu, X Wang
}

\begin{abstract}
Objective: To investigate whether the different concentrations of morphine after coronary perfusion have myocardial protection.

Subjects and method: Forty-five patients undergoing heart valve replacement were randomly divided into three groups of 15 patients: group A (morphine $2 \mu \mathrm{mol} / \mathrm{L}$ in the cardioplegic solution), group $B$ (morphine $4 \mu \mathrm{mol} / \mathrm{L}$ in the cardioplegic solution) and group $C$ (no morphine in the cardioplegic solution). The three groups were monitored before induction (T1), five minutes before (T2) and five minutes after (T3) cardiopulmonary bypass (CPB), perioperative (T4) for haemodynamic parameters, two hours after $C P B$ (T5) and 24 hours after $C P B$ (T6). The postoperation incidence of severe ventricular arrhythmia and low cardiac output, CPB transit time, aortic cross-clamp time, defibrillation time, duration of ventilation and intensive care unit (ICU) and hospital stay were recorded.

Results: The levels of cardiac troponin I (cTnI) at T5 and T6 in group A and group B were significantly lower than those in group $C(\mathrm{p}<0.05)$, and at T6 in group $B$, were lower than those in group $A(\mathrm{p}<$ 0.05). The levels of $C K-M B$ at T6 in group $B$ were lower than those in group $C(\mathrm{p}<0.05)$. The morphological changes in group $A$ and group $B$ were less than those in group $C$; and the least in group $B$.

Conclusion: Morphine at concentrations of $2 \mu \mathrm{mol} / \mathrm{L}$ and $4 \mu \mathrm{mol} / \mathrm{L}$ after coronary perfusion on cardiac valve replacement with $C P B$ has myocardial protection; 4 umol/L of morphine provides more myocardial protection.
\end{abstract}

Keywords: Coronary perfusion, morphine, myocardial protection

WIMJ Open 2014; 1 (3): 107

\section{INTRODUCTION}

Myocardial ischaemic reperfusion injury is the enhanced myocardial cell metabolic disturbance and structural damage when ischaemic hearts restore blood flow. Morphine, the agonists of $\delta$ and $\kappa$ opioid receptors, having both early and late preconditioning effects, plays a significant role in cardioprotection $(1,2)$. In the model of ischaemic preconditioning, using morphine can reduce the reperfusion injury. This study is focussed on cardioprotection under different concentration of morphine preconditioning in the aspect of haemodynamics, cardiac arrhythmia, myocardial enzyme, cardiac troponin I (cTnI) and the histological changes of cardiomyocytes.

From: Department of Anesthesiology, First Affiliated Hospital of Nanchang University, Jiangxi 330006, China.

Correspondence: Dr S Chen, Department of Anesthesiology, First Affiliated Hospital of Nanchang University, Jiangxi 330006, China. E-mail: shibiaochen999@gmail.com

\section{SUBJECTS AND METHODS}

Forty-five patients between the ages of 33 and 66 years who were undergoing heart valve replacement were selected. Exclusion criteria included (i) New York Heart Association (NYHA) classification II or III, (ii) normal liver function and (iii) no obvious phenomenon of myocardial ischaemia detected by electrocardiogram (ECG) preoperation. They were randomly divided into three groups: morphine 1 group (Group A), morphine 2 group (Group B) and control group (Group C). Each group had 15 patients.

All patients were given cardiac diuresis and potassium supplement therapy. Anaesthesia was induced with midazolam, fentanyl and vecuronium bromide. General anaesthesia was maintained with fentanyl intravenous injection and sevoflurane inhalation. All the patients underwent open heart surgery with an extracorporeal membrane oxygenator (Sarns 8000). Cardioplegic solution having $2 \mu \mathrm{mol} / \mathrm{L}$ morphine was prepared to St-Thomas II cold crystalloid. Group A underwent aortic cross-clamp initially with $20 \mathrm{ml} / \mathrm{kg}$ 
morphine perfusion (12-15); then perfusion with $10 \mathrm{ml} / \mathrm{kg}$ every 30 minutes or to the beginning of electrocardiac activity. Cardioplegic solution having $4 \mu \mathrm{mol} / \mathrm{L}$ morphine was prepared to St-Thomas II cold crystalloid. Group B underwent aortic cross-clamp initially with $20 \mathrm{ml} / \mathrm{kg}$ morphine perfusion; then perfusion with $10 \mathrm{ml} / \mathrm{kg}$ every 30 minutes or to the beginning of electrocardiac activity. Group $\mathrm{C}$ underwent the same procedure using cardioplegic solution without morphine.

The three groups were monitored before induction (T1), five minutes before (T2) and five minutes after (T3) cardiopulmonary bypass (CPB), for perioperative (T4) haemodynamic parameters such as heart rate (HR), mean arterial pressure (MAP) and central venous pressure (CVP), two hours after CPB (T5) and 24 hours after CPB (T6). The postoperative incidence of severe ventricular arrhythmia and low cardiac output, CPB transit time, aortic cross-clamp time, defibrillation time, duration of ventilation, and intensive care unit (ICU) and hospital stay were recorded. The venous blood samples $(3 \mathrm{ml})$ were taken at $\mathrm{T} 2, \mathrm{~T} 5$ and T6. Serum was harvested by centrifugation at $2000 \mathrm{rpm}$ for 20 minutes and then stored $-20{ }^{\circ} \mathrm{C}$ in the refrigerator. Creatine kinase (CK), and the MB-isoenzyme of CK (CKMB), lactate dehydrogenase (LDH), alpha-hydroxybutyrate dehydrogenase $(\alpha-\mathrm{HBDH})$ and cTnI were detected by a fully automated enzyme-linked immunosorbent assay (ELISA) system according to the manual after the temperature of the samples was restored to normal. Two patients each from the three groups were randomly selected. A small clip of their right atrial appendages was taken before $\mathrm{CPB}$ and at preoral cavity intubation. A small clip of their right atrial appendages (not ligated) was taken at the time between defibrillation and cessation of $\mathrm{CPB}$ and removal of intubation. These clips were embedded in paraffin and then the morphological changes of apoptosis were observed by electronic microscope.

Statistical analysis was handled by SPSS 17.0 software. All values are expressed as mean $\pm \mathrm{SD}$. Means were analysed and compared by analysis of variance (ANOVA).
To the significant difference, multiple comparisons were carried out by logarithmic standard deviation. Rank-sum test was applied in abnormal distribution data, while Chi-square test was applied in enumeration data. Statistical differences were considered significant if the p-value was $<0.05$.

This study was approved by the ethical committee of our medical college. The patients signed informed consent.

\section{RESULTS}

The patients in the three groups ranged in age from 33 to 66 years; mean age was $49.78 \pm 8.53$ years. Men accounted for $46.67 \%$, women $53.33 \%$. The mean weight was $51.78 \pm 7.31$ (range $36-67$ ) kg; 51.11\% were NYHA classification II and $48.89 \%$ were classification III. There was a significant difference among the patients' age, gender, weight and NYHA classification in the three groups.

The haemodynamic parameters of the patients are listed in Table 1. The values of MAP were lower at T2, T3 and T4 than at T1, but HR and CVP were higher. However, there were no significant differences among the groups $(p>$ $0.05)$.

There were also no significant differences in operative data among the groups $(p>0.05)$ in terms of: CPB transit time, aortic cross-clamp time, defibrillation time, duration of ventilation, and ICU and hospital stay (Table 2). Incidence rates of ventricular arrhythmia were lower in groups A and B than in group C. However, there were no significant differences $(p>0.05)$ among the groups.

The data for myocardial enzyme spectrum and cTnI are summarized in Table 3. The CK-MB values in serum were lower in group $\mathrm{B}$ than in group $\mathrm{C}(p<0.05)$ at $\mathrm{T} 6$. The $\mathrm{cTnI}$ values were lower in serum in group $\mathrm{A}$ and $\mathrm{B}$ than those in group C $(p<0.05)$, and group B levels were lower than those in group A $(p<0.05)$. There were no significant differences among the groups in $\mathrm{CK}$, $\mathrm{LDH}$ and $\alpha-\mathrm{HBDH}$ values.

Before CPB, myocardial myofibrils were regularly arranged, and the structure of the mitochondria was clearly visible (Fig. 1A). After CPB in group A, myocardial myofibrils were arranged disorderly; the structure was blurry,

Table 1: Changes in haemodynamic parameters $(x \pm \mathrm{SD})$

\begin{tabular}{ccccrrr}
\hline Parameters & Group & Cases (n) & \multicolumn{1}{c}{ T1 } & \multicolumn{1}{c}{ T2 } & \multicolumn{1}{c}{ T3 } & \multicolumn{1}{c}{ T4 } \\
\hline HR & A & 15 & $95.07 \pm 15.69$ & $101.53 \pm 14.89$ & $106.33 \pm 8.30$ & $100.53 \pm 6.63$ \\
$(\mathbf{b} / \mathbf{m i n})$ & $\mathrm{B}$ & 15 & $92.73 \pm 17.97$ & $95.33 \pm 11.29$ & $98.80 \pm 10.69$ & $96.73 \pm 5.48$ \\
& $\mathrm{C}$ & 15 & $93.93 \pm 19.34$ & $101.20 \pm 18.19$ & $105.73 \pm 12.67$ & $101.60 \pm 7.61$ \\
$\mathbf{M A P}$ & $\mathrm{A}$ & 15 & $83.67 \pm 8.30$ & $68.73 \pm 8.38$ & $69.27 \pm 6.34$ & $79.53 \pm 8.96$ \\
& $\mathrm{~B}$ & 15 & $88.13 \pm 6.53$ & $72.20 \pm 6.90$ & $70.00 \pm 7.24$ & $74.40 \pm 6.15$ \\
& $\mathrm{C}$ & 15 & $81.87 \pm 9.92$ & $74.20 \pm 9.36$ & $72.60 \pm 4.17$ & $74.00 \pm 6.91$ \\
& $\mathrm{~A}$ & 15 & $9.13 \pm 3.02$ & $9.47 \pm 2.00$ & $10.73 \pm 2.25$ & $10.53 \pm 2.50$ \\
$\mathbf{C V P}$ & $\mathrm{B}$ & 15 & $8.87 \pm 2.20$ & $9.13 \pm 1.64$ & $9.47 \pm 1.46$ & $8.93 \pm 1.28$ \\
$\left(\mathbf{c m} \mathbf{H}_{\mathbf{2}} \mathbf{O}\right)$ & $\mathrm{C}$ & 15 & $9.40 \pm 2.75$ & $9.47 \pm 2.23$ & $10.47 \pm 2.36$ & $10.20 \pm 2.40$ \\
\hline
\end{tabular}

$\mathrm{HR}$ - heart rate; $\mathrm{MAP}$ - mean arterial pressure; $\mathrm{CVP}$ - central venous pressure 
Table 2: Operative procedure data among the groups

\begin{tabular}{lccccccc}
\hline Group & $\begin{array}{c}\text { CPB transit } \\
\text { time (min) }\end{array}$ & $\begin{array}{c}\text { Aortic } \\
\text { cross-clamp } \\
\text { time (min) }\end{array}$ & $\begin{array}{c}\text { Duration of } \\
\text { ventilation (h) }\end{array}$ & $\begin{array}{c}\text { Duration of } \\
\text { ICU stay (h) }\end{array}$ & $\begin{array}{c}\text { Defibrillation } \\
\text { time (min) }\end{array}$ & $\begin{array}{c}\text { Hospital } \\
\text { stay (d) }\end{array}$ & $\begin{array}{c}\text { Ventricular } \\
\text { arrhythmia, } \\
\text { n (\%) }\end{array}$ \\
\hline $\mathrm{A}(\mathrm{n}=15)$ & $97.60 \pm 22.12$ & $64.47 \pm 20.10$ & $21.20 \pm 2.68$ & $30.40 \pm 10.99$ & $0.80 \pm 0.94$ & $9.80 \pm 1.61$ & $2(13.33)$ \\
$\mathrm{B}(\mathrm{n}=15)$ & $92.73 \pm 19.41$ & $58.73 \pm 16.16$ & $20.60 \pm 2.38$ & $30.40 \pm 10.99$ & $0.53 \pm 0.92$ & $9.53 \pm 1.30$ & $1(6.67)$ \\
$\mathrm{C}(\mathrm{n}=15)$ & $96.13 \pm 23.92$ & $63.53 \pm 20.07$ & $22.53 \pm 2.77$ & $35.20 \pm 12.39$ & $0.73 \pm 0.70$ & $9.53 \pm 1.36$ & $4(26.67)$ \\
\hline
\end{tabular}

$\mathrm{CPB}$ - cardiopulmonary bypass; ICU - intensive care unit

Table 3: Comparison of myocardial enzymes and cardiac troponin I

\begin{tabular}{|c|c|c|c|c|c|}
\hline Index & Groups & Cases (n) & $\mathbf{T} 2$ & T5 & T6 \\
\hline \multirow{3}{*}{ CK } & A & 15 & $51.73 \pm 36.18$ & $542.53 \pm 278.32$ & $721.00 \pm 236.64$ \\
\hline & B & 15 & $39.07 \pm 12.99$ & $339.40 \pm 125.12$ & $563.87 \pm 179.79$ \\
\hline & $\mathrm{C}$ & 15 & $50.80 \pm 24.62$ & $521.60 \pm 286.30$ & $665.40 \pm 246.76$ \\
\hline \multirow{3}{*}{ LDH } & A & 15 & $225.67 \pm 63.12$ & $418.60 \pm 110.52$ & $522.93 \pm 124.05$ \\
\hline & B & 15 & $226.53 \pm 56.76$ & $383.40 \pm 383.40$ & $471.93 \pm 143.62$ \\
\hline & $\mathrm{C}$ & 15 & $236.00 \pm 42.25$ & $429.80 \pm 97.07$ & $556.67 \pm 140.49$ \\
\hline \multirow{3}{*}{$\alpha-H B D H$} & A & 15 & $155.93 \pm 36.78$ & $353.93 \pm 142.39$ & $445.73 \pm 167.49$ \\
\hline & B & 15 & $167.00 \pm 41.50$ & $292.33 \pm 81.12$ & $381.20 \pm 83.68$ \\
\hline & $\mathrm{C}$ & 15 & $157.20 \pm 31.32$ & $278.07 \pm 65.84$ & $380.07 \pm 94.84$ \\
\hline \multirow{3}{*}{ CK-MB } & A & 15 & $12.80 \pm 2.86$ & $66.93 \pm 25.01$ & $43.00 \pm 15.80$ \\
\hline & B & 15 & $11.27 \pm 3.75$ & $65.47 \pm 19.63$ & $34.73 \pm 10.63^{\mathrm{a}}$ \\
\hline & $\mathrm{C}$ & 15 & $11.67 \pm 4.39$ & $60.60 \pm 18.63$ & $47.73 \pm 12.45$ \\
\hline \multirow{3}{*}{ cTnI } & A & 15 & $112.10 \pm 20.40$ & $355.31 \pm 47.25^{b}$ & $446.71 \pm 33.86^{b}$ \\
\hline & B & 15 & $114.89 \pm 25.40$ & $348.89 \pm 40.07^{b}$ & $411.08 \pm 36.49^{b, c}$ \\
\hline & $\mathrm{C}$ & 15 & $122.37 \pm 30.33$ & $391.29 \pm 51.62$ & $506.84 \pm 26.95$ \\
\hline
\end{tabular}

Data are means $\pm \mathrm{SD}$. Compared with $\mathrm{C},{ }^{\mathrm{a}} p<0.05,{ }^{\mathrm{b}} p<0.05$; Compared with $\mathrm{A},{ }^{\mathrm{c}} p<0.05$

$\mathrm{CK}$ - creatine kinase; LDH - lactate dehydrogenase; $\alpha-\mathrm{HBDH}$ - alpha-hydroxybutyrate dehydrogenase;

CK-MB - MB-isoenzyme of CK; cTnI - cardiac troponin I
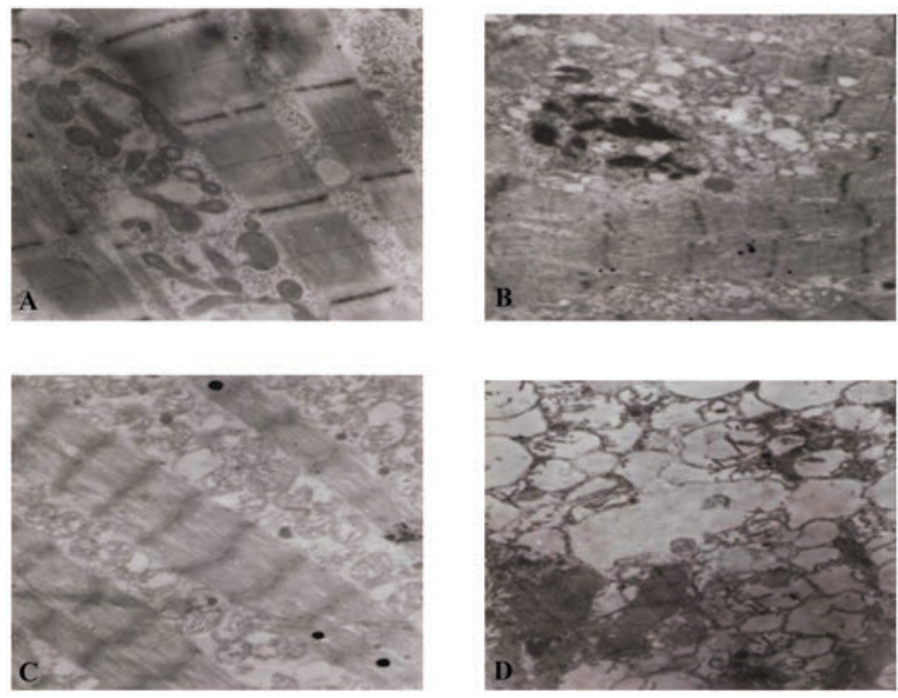

Fig. 1: Morphology of myocardial myofibrils: (A) before cardiopulmonary bypass (CPB), (B) Group A after CPB, (C) Group B after $\mathrm{CPB}$ and (D) Group C after CPB. mitochondrial structure showed vacuoles, and cristae had dissolved and disappeared; there was chromatin condensation and early apoptosis (Fig. 1B). After CPB in group B, myocardial myofibrils were arranged regularly, and the structure was clearly visible; mitochondrial cristae were partially dissolved (Fig. 1C). After CPB in group C, myocardial myofibrils were disorderly, myofibrils were dissolved and the mitochondrial structure was vague and vacuolar; most of the cristae had dissolved and disappeared, and there was cell apoptosis (Fig. 1D).

\section{DISCUSSION}

In 1996, Schultz et al (3) found that myocardial infarct size was reduced by giving rats intravenous morphine that mimics the cardioprotective effect of ischaemic preconditioning. That may have been the first report on ischaemic preconditioning involving morphine. Subsequently, Liang and Gross (4), Miki et al (5), Wong and Wu (6), Gross (7) and Jiang et al (8) have proposed that morphine has broad clinical 
application prospects for cardioprotection before opioids were developed. Morphine, a non-selective opioid receptor agonist (9), mainly activates $\mu$-opioid receptor and can also activate $\delta$ - and $-\kappa$ receptors simultaneously. It is used broadly in anaesthetization, analgesia, myocardial infarction and management of acute left-sided heart failure. Several investigators $(4,5)$ have demonstrated that morphine preconditioning has a ceiling effect. Morphine has improved protective precon-ditioning effects at the concentration of $0.5-10 \mu \mathrm{mol} / \mathrm{L}$. But at the concentration of $10 \mu \mathrm{mol} / \mathrm{L}$ or higher, morphine pre-conditioning effect does not improve. Yan (10) found that morphine at a concentration of $2 \mu \mathrm{mol} / \mathrm{L}$ had a better effect than $1 \mu \mathrm{mol} / \mathrm{L}$ in cardioprotection in clinical practice. Now that these studies have demonstrated that morphine has cardioprotection at low concentration, we speculated that morphine at a higher concentration has a better cardio-protective effect.

This study investigated whether the different concentrations of morphine preconditioning after coronary perfusion have myocardial protection. We increased the concentration of morphine, and used selected haemodynamics, cardiac arrhythmia, myocardial enzyme, cTnI and the histological changes of cardiomyocytes as examination indicators. There are many factors that influence haemodynamics. Cardiac arrhythmia reflects the change of electrical activity of the myocardial cell. Myocardial cells are abundant in CK, CK-MB and LDH, and serum levels are elevated when myocardial cells are injured. Cardiac troponin I is a subunit of cardiac troponin and a biomarker of cardiac damage. It has high sensitivity and can even detect ultra microstructure damage, so it is one of the acknowledged indicators that detect cardiac damage (11). Electron microscopy was used to observe the morphologic change in cardiac cells, which reflects cardiac damage at the cellular level.

The present study shows that the levels of cTnI at T5 and T6 in groups A and B were significantly lower than those in group $\mathrm{C}(p<0.05)$, and at T6 in group $\mathrm{B}$, were lower than those in group A $(p<0.05)$. This demonstrates that cardiomyocyte injuries were lower in morphine groups, and 4 $\mu \mathrm{mol} / \mathrm{L}$ morphine had a better protective effect. The results of electron microscopy showed that myocardial damage was lower in group A and group B than in group C, and group B was better than group A, indicating that morphine $4 \mu \mathrm{mol} / \mathrm{L}$ cardioplegic solution played an important role in maintaining the structures of cardiomyocytes in the process of ischaemic preconditioning. The levels of $\mathrm{CK}, \mathrm{LDH}$ and $\alpha-\mathrm{HBDH}$ were elevated at two hours after CPB (T5) and 24 hours after CPB (T6) which indicates that cardiomyocytes were damaged. But there were no significant differences among the groups $(p>$ 0.05). The levels of CK-MB at 24 hours after CPB (T6) in group B were significantly lower than those in group C, indicating that morphine can reduce myocardial damage in the process of ischaemic preconditioning. Compared with group C, groups A and B had lower postoperative incidence of severe ventricular arrhythmia which indicates that morphine cardioplegic solution can stabilize electrical activity of myocardial cells and inhibit the incidence of ventricular arrhythmia by ischaemic reperfusion.

In summary, $2 \mu \mathrm{mol} / \mathrm{L}$ or $4 \mu \mathrm{mol} / \mathrm{L}$ morphine after coronary perfusion has the effect of myocardial protection in patients undergoing cardiac valve replacement with cardiopulmonary bypass; $4 \mu \mathrm{mol} / \mathrm{L}$ morphine after coronary perfusion has more myocardial protection.

\section{ACKNOWLEDGEMENTS}

This work is supported by scientific technology programme of Jiangxi Provincial Education Department (GJJ11349).

\section{REFERENCES}

1. Peart JN, Gross GJ. Exogenous activation of delta- and kappa-opioid receptors affords cardioprotection in isolated murine heart. Basic Res Cardiol 2004; 99: 29-37.

2. Frässdorf J, Weber NC, Obal D, Toma O, Müllenheim J, Kojda G et al. Morphine induces late cardioprotection in rat hearts in vivo: the involvement of opioid receptors and nuclear transcription factor kappaB. Anesth Analg 2005; 101: 934-41.

3. Schultz JE, Hsu AK, Gross GJ. Morphine mimics the cardioprotective effect of ischemic preconditioning via a glibenclamide-sensitive mechanism in the rat heart. Circ Res 1996; 78: 1100-4.

4. Liang BT, Gross GJ. Direct preconditioning of cardiac myocytes via opioid receptors and $\mathrm{K}_{\mathrm{ATP}}$ channels. Circ Res 1999; 84: 1396-1400.

5. Miki T, Cohen MV, Downey JM. Opioid receptor contributes to ischemic preconditioning through protein kinase $\mathrm{C}$ activation in rabbits. Mol Cell Biochem 1998; 186: 3-12.

6. Wong TM, Wu S. Role of kappa opioid receptor in cardioprotection of preconditioning: implications in cardiac surgery. J Card Surg 2002; 17: 462-4.

7. Gross GJ. Role of opioids in acute and delayed preconditioning. J Mol Cell Cardiol 2003; 35: 709-18.

8. Jiang X, Shi E, Nakajima Y, Sato S, Ohno K, Yue H. Cyclooxygenase1 mediates the final stage of morphine-induced delayed cardioprotection in concert with cyclooxygenase-2. J Am Coll Cardiol 2005; 45: $1707-15$.

9. Ela C, Barg J, Vogel Z, Hasin Y, Eilam Y. Distinct components of morphine effects on cardiac myocytes are mediated by the kappa and delta opioid receptors. J Mol Cell Cardiol 1997; 29: 711-20.

10. Yan $X$. The effects of adding morphine into cardioplegia on cardioprotection during cardiopulmonary bypass in children. Global $\mathrm{J}$ Med Hyg 2013 Jan 29 (In press). Available from: http://medicinehygiene.idnwhois.org/article-77033.html

11. Ni CY. Cardiac troponin I: a biomarker for detection and risk stratification of minor myocardial damage. Clin Lab 2001; 47: 483-92.

Submitted 20 Nov 2013

Accepted 26 Nov 2013

Published 06 Nov 2014

Online: http://www.mona.uwi.edu/wimjopen/article/1607

(c) Chen et al 2014.

This is an open access article made freely available under Creative Commons Attribution 4.0 International (CC BY 4.0). Users are free to share, copy and adapt this work as long as the copyright holder (author) is appropriately and correctly credited. See http://creativecommons.org /licences/by/4.0/deed.en_us for more information. 